\title{
Performance Enhancement of Nylon/Kevlar Fiber Composites Through Viscoelastically Generated Pre-Stress
}

\author{
Adnan Fazal, Kevin S. Fancey \\ School of Engineering, University of Hull, HU6 7RX, UK
}

\begin{abstract}
Kevlar-29 fibers have high strength and stiffness but nylon 6,6 fibers have greater ductility. Thus by commingling these fibers prior to molding in a resin, the resulting hybrid composite may be mechanically superior to the corresponding single fiber-type composites. The contribution made by viscoelastically generated pre-stress, via the commingled nylon fibers, should add further performance enhancement. This paper reports on an initial study into the Charpy impact toughness and flexural stiffness of hybrid (commingled) nylon/Kevlar fiber viscoelastically prestressed composites at low fiber volume fractions. The main findings show that (i) hybrid composites (with no pre-stress) absorb more impact energy than Kevlar fiber-only composites; (ii) pre-stress further increases impact energy absorption in the hybrid case by up to $33 \%$; (iii) pre-stress increases flexural modulus by $\sim 40 \%$ in the hybrid composites. These findings are discussed in relation to practical composite applications. POLYM. COMPOS., 35:931-938, 2014. (c) 2013 Society of Plastics Engineers
\end{abstract}

\section{INTRODUCTION}

Although pre-stressed concrete is an established structural material, the exploitation of pre-stress in polymeric composite structures seems to be comparatively rare. Residual stresses within composite moldings are normally seen as an unfortunate consequence of differential shrinkage from the processing route [1] or as a means (when purposely applied) to align fibers in filament-wound structures [2,3]. Research papers focused on enhancing the mechanical properties of polymeric matrix composites (PMCs) through pre-stress are uncommon.

An elastically pre-stressed PMC (EPPMC) is directly comparable to pre-stressed concrete, in that fibers within the composite are stretched to maintain an elastic strain as the matrix cures. On solidification, this produces compressive stresses within the matrix, counterbalanced by

Correspondence to: K.S. Fancey; e-mail: k.s.fancey@hull.ac.uk DOI 10.1002/pc.22737

Published online in Wiley Online Library (wileyonlinelibrary.com).

(C) 2013 Society of Plastics Engineers residual fiber tension. Studies comparing unidirectional glass fiber EPPMCs, with unstressed counterparts, have indicated increases in tensile strength and elastic modulus of $\sim 25 \%$ and $\sim 50 \%$ respectively [4]. Impact resistance and flexural properties (stiffness and strength) have also been found to increase by up to $33 \%[5,6]$. Explanations for these improvements emanate from matrix compression and fiber tension effects: these may (i) impede or deflect propagating cracks and (ii) reduce composite strains from external tensile or bending loads [4-6]. Although elastic pre-stressing should offer improved mechanical properties without the need to increase mass or section dimensions within a composite structure, there are potential drawbacks. Fiber orientation, length, and spatial distribution would be restricted by the application of fiber tension during matrix curing, thereby compromising mold geometry. Moreover, the matrix (being polymeric) may undergo localized creep at the fiber-matrix interface regions, in response to the compressive stresses imposed by the fibers: hence the pre-stress effect could deteriorate with time [7].

A viscoelastically pre-stressed PMC (VPPMC) avoids these drawbacks. Here, polymeric fibers are subjected to tensile (viscoelastic) creep; the creep load is then released before the fibers are molded into a matrix. After matrix solidification, the strained fibers (in residual tension) continue to attempt viscoelastic recovery, thereby producing compressive stresses within the matrix, similar to an EPPMC. Nevertheless, in contrast with EPPMC processing, there are no constraints on fiber or mold geometries, as VPPMC fiber stretching and molding operations are totally separate. Furthermore, since the pre-stress is generated from fiber viscoelasticity, any potential for deterioration through localized matrix creep would be offset by an active response from longer term recovery mechanisms within the polymeric fibers [7].

From Charpy impact tests, VPPMC samples have been found to absorb typically 25-30\% more impact energy than their control (unstressed) counterparts, with some samples reaching increases of 50\% [7-12]. Tensile tests [13] have demonstrated increases in strength, modulus 
and energy absorption exceeding 15, 30, and 40\% respectively; also three-point bend tests [14] have shown flexural modulii to be $\sim 50 \%$ greater than corresponding control samples. All these findings [7-14] are based on VPPMCs with pre-stress provided by nylon 6,6 fibers. Most recently however, we have found increases of 20$40 \%$ in flexural modulus from VPPMCs based on ultrahigh molecular weight polyethylene (UHMWPE) fibers [15]. Similarly, other researchers have demonstrated VPPMCs based on bamboo and, although flexural modulii were increased by only $12 \%$, flexural toughness was improved by $28 \%$ [16]. Although potential alternatives may be emerging, VPPMCs based on nylon 6,6 fibers remain (currently) the most established route, the prestress being demonstrated to last at least 20 years at a constant $40^{\circ} \mathrm{C}[11]$.

Despite the potential benefits that VPPMC principles may offer, criticisms associated with the mechanical properties of fibers used for generating pre-stress could impede the development of VPPMC technology for practical composite applications. Clearly, a VPPMC requires fibers to possess appropriate viscoelastic characteristics, hence common structural PMC fiber materials (glass, carbon) must be ruled out. Similarly, some high performance polymeric fibers may be unsuitable for generating viscoelastic pre-stress. For example, aramid fibers will undergo tensile creep but the resulting strain is very low; moreover, creep strain-time curves appear to show significant Maxwell element behavior (elastic spring in series with a viscous dashpot) [17, 18]. Both aspects reduce opportunities for appropriate long-term viscoelastic recovery, making aramid fibers an unlikely contender.

An alternative route to exploiting VPPMC technology for load-bearing composite applications would be to produce hybrid composites by commingling fibers for viscoelastically generated pre-stress with common structural fibers. This paper reports on a preliminary evaluation (by Charpy and flexural testing) of hybrid VPPMCs consisting of commingled nylon/Kevlar fibers.

\section{BACKGROUND}

\section{Potential Benefits from Hybrid VPPMCs}

Toughness (energy absorption) is generally associated with a combination of high ductility and high strength. Although Kevlar-29, as a polymer fiber, is well known for its high strength, the strain-to-failure (STF) is substantially less (at $\sim 4 \%$ ) than lower strength nylon 6,6 fiber (14-22\%) [19]. Thus by commingling these two fibers, the resulting hybrid composite may exhibit greater property improvement capabilities over the corresponding single fiber type composites. Graphite [20] and glass [21] fibers, when hybridized with ductile polymeric fibers, have produced composites demonstrating enhanced impact energy absorption. The contribution made by pre- stress, via commingled nylon fibers, adds a further dimension to impact performance. Previous Charpy impact studies [7-12] have indicated that increased energy absorption in VPPMCs arises from residual shear stresses at the fiber-matrix interface regions promoting energy absorbing fiber debonding (delamination) over transverse fracture. This has also been observed in EPPMCs [5]. Therefore, a nylon/Kevlar fiber VPPMC may also demonstrate improved impact toughness by the same means.

In flexural testing, stiffer fibers should be expected to produce stiffer composites, as the tensile region in bending will depend on Young's modulus $(E)$ of the fibers. Although $E$ for Kevlar-29 (58 GPa) is comparable with that of UHMWPE fiber (87 GPa), $E$ for fibers of nylon 6,6 is substantially lower $(3.3 \mathrm{GPa})$ [19]. In contrast, three-point bend tests on unstressed nylon 6,6 fiberreinforced composite samples [14] show only a modest reduction in flexural modulus $(\sim 2.8 \mathrm{GPa})$ relative to those using UHMWPE fiber ( $\sim 4 \mathrm{GPa})$ [15] and this smaller difference may be attributed to the low fiber volume fraction, $V_{\mathrm{f}}(8 \%)$, in these two cases. Nevertheless, the effect of pre-stress generated by nylon 6,6 fibers commingled with Kevlar-29 fibers may, even at low $V_{\mathrm{f}}$, provide a significant increase in flexural modulus.

As reported in the "Introduction" section, VPPMCs based on nylon 6,6 fiber [14] and UHMWPE fiber [15] have demonstrated increases in flexural modulus of up to $50 \%$ compared with control counterparts. Comparable increases have been observed with EPPMCs, the effect being attributed to deflection-dependent forces opposing the applied bending load [6] and a more collective response to bending forces from the pre-tensioned fibers [22]. A further mechanism has been proposed [14], in which the compressive pre-stress shifts the neutral axis in bending. Tensile forces below the neutral axis are reduced, which increases bending stiffness; there is also greater compression above the neutral axis. Since matrix modulus can be greater in compression [23], the latter may also contribute to increased bending stiffness.

\section{Composite Sample Production and Evaluation}

As with previous studies involving Charpy impact and flexural stiffness evaluation [7-12, 14, 15], open casting offered the simplest composite sample production method. Also in common with earlier work, mechanical evaluation necessitated the comparison of VPPMC "test" samples with unstressed "control" counterparts. To ensure no differences between test and control samples (other than pre-stress effects), each batch required simultaneous test and control sample production, followed by inspection of molded cross-sections to compare fiber spatial distributions.

Previous flexural stiffness measurements for VPPMCs based on nylon 6,6 fiber [14] and UHMWPE fiber [15] involved three-point bend tests on samples using a freely suspended load. A deflection reading was taken $5 \mathrm{~s}$ after 
applying the load to obtain (as close as possible) the elasticity modulus and the same principle was adopted for this study. From the conventional three-point beam-bending relationship [24], the flexural modulus $E(t)$ can be determined from deflection $\delta(t)$ at the centre of the beam at time $t$ (i.e., $5 \mathrm{~s}$ ) using:

$$
E(t)=\frac{P L^{3}}{48 \delta(t) I}
$$

where $P$ is the applied load, $L$ is the span and $I$, the second moment of area, is $\left(b h^{3} / 12\right)$ for a rectangular sample of width $b$ and thickness $h$.

\section{EXPERIMENTAL}

\section{Production and Inspection of Composite Samples}

Fiber reinforcement was from continuous multifilament nylon 6,6 yarn (140 filaments, $27.5 \mu \mathrm{m}$ filament diameter) and Kevlar-29 yarn (120 filaments, $18 \mu \mathrm{m}$ filament diameter), supplied by Goodfellow Cambridge, UK. Batches of composite samples were required for Charpy impact testing and flexural stiffness evaluation. In all cases, the nylon yarn was annealed in a fan-assisted oven $\left(150^{\circ} \mathrm{C}, 0.5 \mathrm{~h}\right)$; this was essential for long-term viscoelastic recovery [7-11]. Moreover, to enable direct comparison, nylon yarn designated for (unstressed) control samples was annealed at the same time. Although annealing would have dehydrated the nylon fibers, we have found that equilibrium water content (by weight measurement) is restored within $\sim 0.5 \mathrm{~h}$ following removal from the oven; also, the annealing process has no significant effect on the mechanical strength of these fibers [13]. Since the Kevlar yarn had no role in viscoelastically generated pre-stress, this was used in as-received condition.

Nylon yarn designated for (pre-stressed) test samples was attached to a bespoke stretching rig and subjected to $340 \mathrm{MPa}$ tensile creep stress for $24 \mathrm{~h}$. From viscoelastic recovery force data [25], this would be expected to produce an axial stress (across the fibers) of $\sim 10 \mathrm{MPa}$ within a VPPMC. The equivalent (annealed) control yarn was positioned in close proximity to the stretching rig for exposure to the same ambient conditions $\left(19.5-21^{\circ} \mathrm{C}, 30-\right.$ $50 \% \mathrm{RH})$. Both yarns were then folded, cut into multiple lengths and brushed into flat ribbons ( $\sim 10 \mathrm{~mm}$ wide). To produce hybrid samples, alternating ribbons of nylon and Kevlar fibers were progressively brushed together to form a randomly mixed bundle for subsequent molding.

For the matrix, a clear-casting polyester resin was used as previously [12, 15], i.e., Cray Valley Norsodyne E9252, mixed with 1\% MEKP catalyst, supplied by CFS Fibreglass Supplies, UK. Room temperature gel time was $\sim 0.25 \mathrm{~h}$ and after $2 \mathrm{~h}$, the resin was sufficiently cured to allow demolding. The open casting of unidirectional continuous fiber composite samples utilized two identical aluminium molds, each with a $10 \mathrm{~mm}$ wide channel. One mold was used for casting a strip of test material, the other for control material, both being cast simultaneously from the same resin mix to produce one batch. Casting was completed within $0.5 \mathrm{~h}$ of the fiber stretching process and, after demolding, the two strips were cut into appropriate lengths and held under a weighted steel strip for 24 $\mathrm{h}$ to prevent any residual stresses causing sample distortion.

For all hybrid composite samples, $V_{\mathrm{f}}$ was $4.5 \%$, consisting of $3.3 \%$ nylon with $1.2 \%$ Kevlar fibers. Each batch for Charpy impact testing comprised five test and five control samples, sample dimensions being $80 \times 10$ $\times 3.2 \mathrm{~mm}$. For flexural testing, just one test and one control sample was produced per batch, sample dimensions being $200 \times 10 \times 3.2 \mathrm{~mm}$. All samples were stored in polythene bags at room temperature $\left(18-22^{\circ} \mathrm{C}\right)$ prior to testing.

To enable a more comprehensive analysis of results, additional composite samples with Kevlar fibers only (3.6\% $V_{\mathrm{f}}$, no pre-stress) were produced, as above, for Charpy impact testing. Furthermore, resin-only samples were molded and cut to appropriate dimensions for both Charpy impact and flexural testing.

Photographic evidence of effects that could adversely influence composite sample characteristics was required, using optical microscopy. This was to ensure that there would be no differences between test and control samples, other than mechanical effects from pre-stress. Ground and polished composite sample cross sections were taken from the molded strips to observe fiber spatial distributions.

\section{Mechanical Evaluation of Composites}

A Ceast Resil 25 Charpy machine with a $7.5 \mathrm{~J}$ hammer was used for impact testing at $3.8 \mathrm{~ms}^{-1}$, operating in accordance with BS EN ISO 179. As observed with previous Charpy-based studies using open-cast polyester matrix samples [7-12], fibers tended to settle towards the bottom of the mold prior to curing. Thus for all our impact tests, samples were mounted with the fiber-rich side facing away from the pendulum hammer and a diagram of this configuration has been previously published [7-9]. For the hybrid composites, three batches (i.e., 15 test and 15 control samples) were each impact tested at a span setting $(L)$ of 60 and $24 \mathrm{~mm}$. These $L$ settings corresponded to BS EN ISO 179 Specimen Types 2 and 3, respectively. Similarly, the additional samples (15 Kevlar and 15 resin-only) were impact tested at both span settings. All samples were tested at 336 h (2 weeks) after molding.

Three-point bend tests with a freely suspended load were performed using a simple test rig (Fig. 1). The setup and procedures were identical to those performed with VPPMC samples of nylon 6,6 fiber and UHMWPE fiber [14, 15], i.e., each sample was mounted horizontally with the molded bottom surface facing downwards and a 


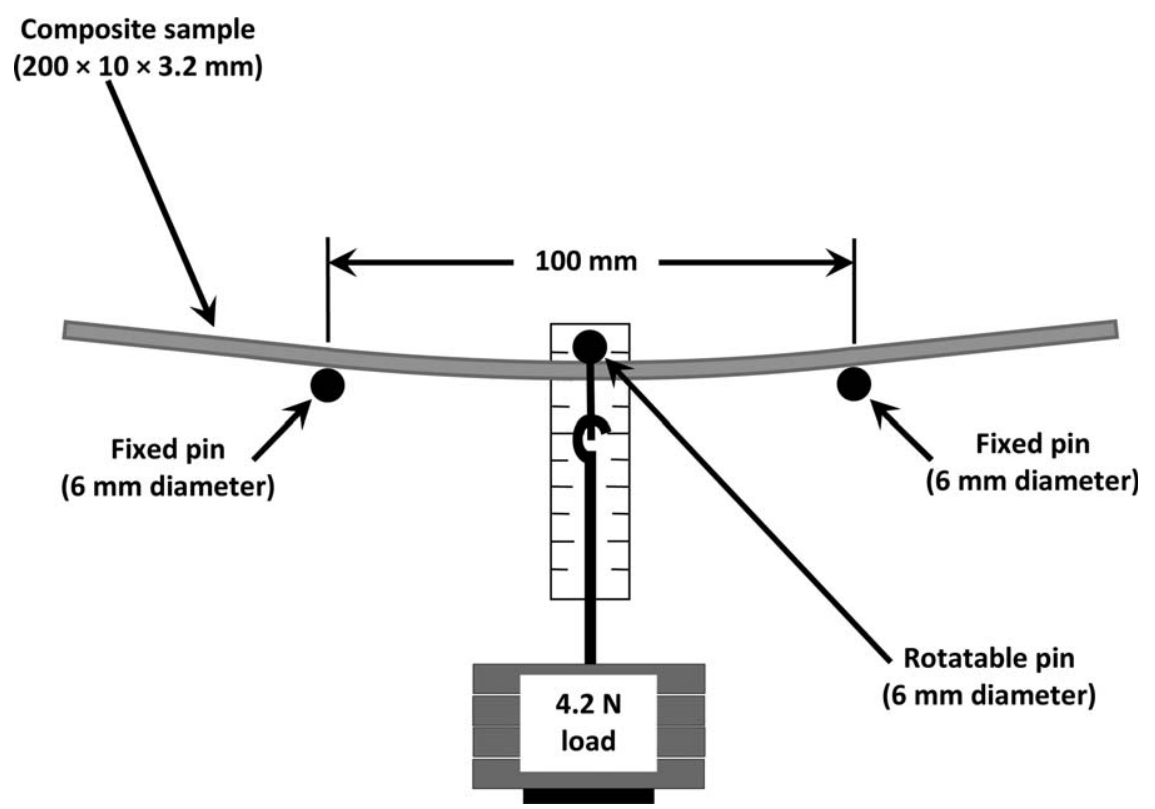

FIG. 1. Schematic of the set-up used for three-point bend testing of samples.

deflection reading was taken at $5 \mathrm{~s}$ after applying the load. Although small deflections restricted measurement precision and accuracy, it was important to ensure that opportunities for specimen damage were minimized. For this study, a load of $4.2 \mathrm{~N}$ was adopted, i.e., similar to the load used for nylon 6,6 fiber VPPMCs [14].

Deflections were measured at $20-21^{\circ} \mathrm{C}$ on each sample just once at $336 \mathrm{~h}$ and $1008 \mathrm{~h}$. Equation 1 was then used to calculate $E(t)$. To improve measurement accuracy, a video recording of each deflection in progress was made. For repeatability, three test and three control hybrid samples (i.e., three batches) and three resin-only samples were evaluated.

\section{RESULTS}

\section{Cross-Sectional Analysis of Composite Samples}

Figure 2 shows representative cross-sections of the hybrid and Kevlar fiber-only composites. Of particular importance is that there appear to be no significant differences in fiber distributions between the test and control hybrid samples. Macroscopically, both test and control samples show similar fiber spatial distributions, the greatest concentration being in the lower half of the molding, caused by fibers settling towards the bottom of the mold during casting. Microscopically, the (smaller) Kevlar fibers are randomly dispersed between the nylon fibers, with no observable disparity between test and control samples.

The macroscopic fiber spatial distribution in the Kevlar fiber-only sample is comparable to the hybrid samples in Fig. 2. These distributions are also similar to those observed in open-cast nylon 6,6 fiber composites using the same resin [12]: this enables Charpy results from the current work to be compared with findings from Ref. [12].

\section{Charpy Impact Tests}

Table 1 shows impact energy data from the hybrid batches. Although both spans show the test samples absorbing more energy than their control counterparts, the pre-stress effect is clearly greater at the $24 \mathrm{~mm}$ setting, an effect also observed with nylon 6,6 fiber VPPMCs [12]. Table 2 shows data from the additional samples. As expected, energy absorption for the resin-only samples is very low. Compared with the control samples in Table 1 however, the Kevlar fiber composite samples also exhibit poor results and these are relatively insensitive to span setting.

Data from Tables 1 and 2 are summarized in Fig. 3. Also shown, for comparison, are impact energy results from Ref. [12], for nylon 6,6 fiber composites with 3.3\% $V_{\mathrm{f}}$, using the same resin, tested at $336 \mathrm{~h}$ after molding. At $24 \mathrm{~mm}$ span (Fig. 3a), the nylon-only composites absorb more energy than the hybrid case, though pre-stressinduced increases are comparable, i.e., 33\% (Table 1) and $39 \%$ [12]. At $60 \mathrm{~mm}$ span (Fig. 3b) however, the situation is reversed as energy absorption by the hybrid composites is less affected by the larger span setting. There is only a small increase in pre-stress-induced energy absorption from the hybrid composites (11.4\% from Table 1), but this is an improvement over the nylon-only case ( $\sim$ zero increase).

Figure 4 shows typical hybrid and Kevlar fiber composite samples after impact testing. The Kevlar composites clearly indicate brittle fracture; in fact, all 15 samples at each span setting fractured into two pieces. 


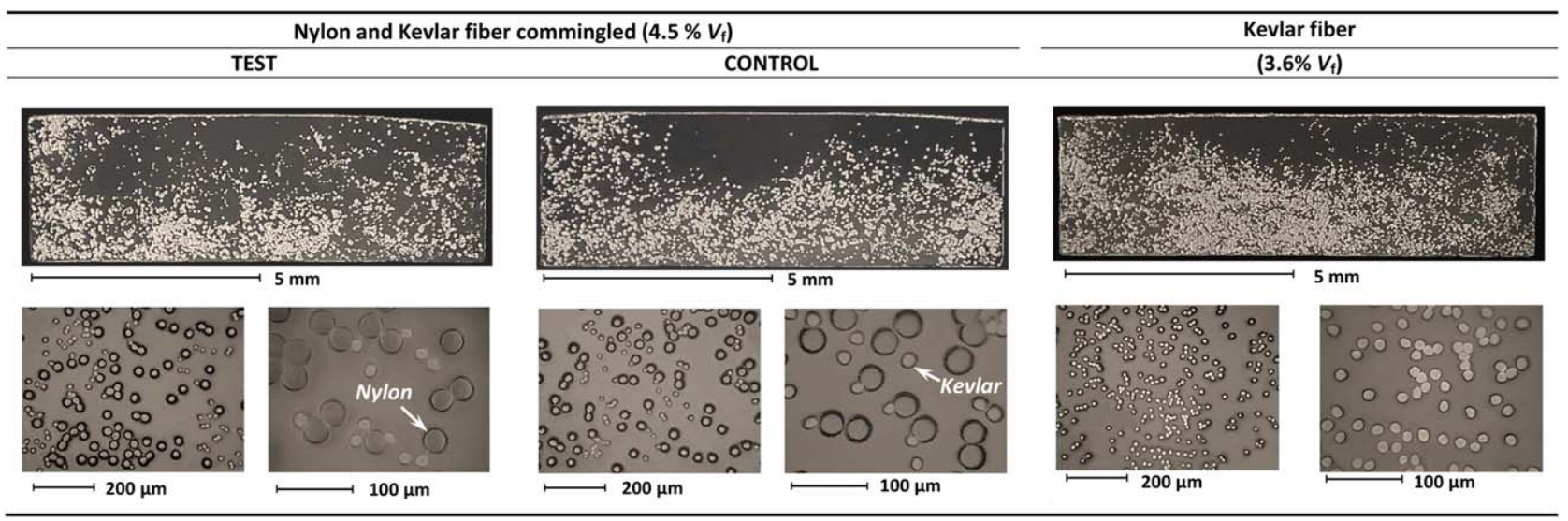

FIG. 2. Representative optical micrograph (polished) sections of the hybrid and Kevlar fiber-only composite samples. [Color figure can be viewed in the online issue, which is available at wileyonlinelibrary.com.]

TABLE 1. Impact test results of hybrid composite sample batches: 5 (pre-stressed) test and 5 (unstressed) control samples per batch.

\begin{tabular}{|c|c|c|c|c|}
\hline \multirow[b]{2}{*}{ Charpy span } & \multicolumn{2}{|c|}{$\begin{array}{l}\text { Mean impact energy } \\
\qquad\left(\mathrm{kJ} \mathrm{m}^{-2}\right)\end{array}$} & \multirow{2}{*}{$\begin{array}{l}\text { Increase in } \\
\text { energy }(\%)\end{array}$} & \multirow{2}{*}{$\begin{array}{l}\text { Mean increase in } \\
\text { energy }(\% \pm S E)\end{array}$} \\
\hline & Test $\pm \mathrm{SE}$ & Control $\pm \mathrm{SE}$ & & \\
\hline \multirow[t]{3}{*}{$24 \mathrm{~mm}$} & $73.5 \pm 1.7$ & $51.3 \pm 1.3$ & 43.2 & $32.9 \pm 8.1$ \\
\hline & $65.2 \pm 3.1$ & $55.8 \pm 1.4$ & 16.9 & \\
\hline & $71.4 \pm 2.6$ & $51.5 \pm 0.6$ & 38.6 & \\
\hline \multirow[t]{3}{*}{$60 \mathrm{~mm}$} & $53.5 \pm 1.9$ & $47.3 \pm 2.0$ & 13.0 & $11.4 \pm 1.1$ \\
\hline & $50.4 \pm 0.9$ & $45.1 \pm 0.8$ & 11.9 & \\
\hline & $44.9 \pm 3.6$ & $41.1 \pm 1.3$ & 9.2 & \\
\hline
\end{tabular}

Total $V_{\mathrm{f}}$ was $4.5 \%$ (3.3\% nylon and $1.2 \%$ Kevlar). SE is the standard error of the mean.

The less wavy fracture profile at $60 \mathrm{~mm}$ span in Fig. 4 may indicate a more pronounced brittle fracture at this setting. In contrast, the hybrid composites show fracture characteristics of a more ductile nature (hinged-break), where energy absorption through fiber-matrix debonding becomes more significant. The hybrid test samples show a greater debonded (lighter) region than their control counterparts. This is consistent with previous observations

TABLE 2. Impact test results from batches of Kevlar fiber composites $\left(3.6 \% V_{\mathrm{f}}\right)$ and resin-only samples; 5 samples per batch.

\begin{tabular}{lcc}
\hline \multirow{2}{*}{ Charpy span } & \multicolumn{2}{c}{ Impact energy $\left(\mathrm{kJ} \mathrm{m}^{-2}\right)$} \\
\cline { 2 - 3 } $24 \mathrm{~mm}$ & $\begin{array}{c}\text { Kevlar } \\
\text { Batch mean } \pm \text { SE }\end{array}$ & $\begin{array}{c}\text { Resin-only } \\
\text { Batch mean } \pm \text { SE }\end{array}$ \\
& $15.2 \pm 0.4$ & $5.4 \pm 0.2$ \\
Mean \pm SE & $17.4 \pm 0.4$ & $5.5 \pm 0.8$ \\
$60 \mathrm{~mm}$ & $18.3 \pm 0.8$ & $4.4 \pm 0.2$ \\
& $17.0 \pm 0.5$ & $5.1 \pm 0.4$ \\
Mean \pm SE & $18.8 \pm 1.4$ & $6.8 \pm 0.7$ \\
\hline
\end{tabular}

$\mathrm{SE}$ is the standard error of the mean. from nylon 6,6 fiber composites [7-12], though the presence of Kevlar fibers reduces the visibility of these regions in Fig. 4.

\section{Flexural Tests}

Table 3 summarizes the flexural modulus results from the three test and three control hybrid samples. Clearly, there is no deterioration in modulus values (test or control) over the age range investigated. In fact, some samples show slightly higher values from re-testing at
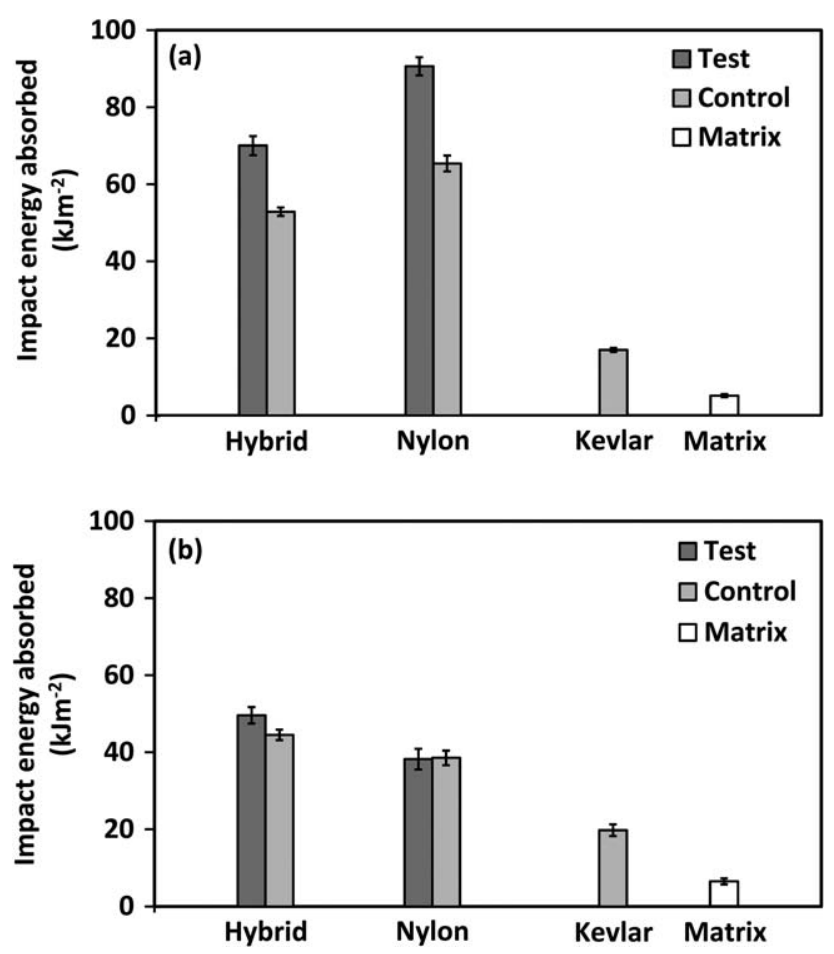

FIG. 3. Mean impact energy data at (a) $24 \mathrm{~mm}$ and (b) $60 \mathrm{~mm}$ spans, from test and control hybrid composite batches (3.3\% $V_{\mathrm{f}}$ nylon, $1.2 \% V_{\mathrm{f}}$ Kevlar) from Table 1. Also shown for comparison are data from nylon fiber-only $\left(3.3 \% V_{\mathrm{f}}\right)$ [12], Kevlar fiber-only $\left(3.6 \% V_{\mathrm{f}}\right)$ and matrix (resin)-only batches from Table 2. All samples were tested at $336 \mathrm{~h}$ after molding. 


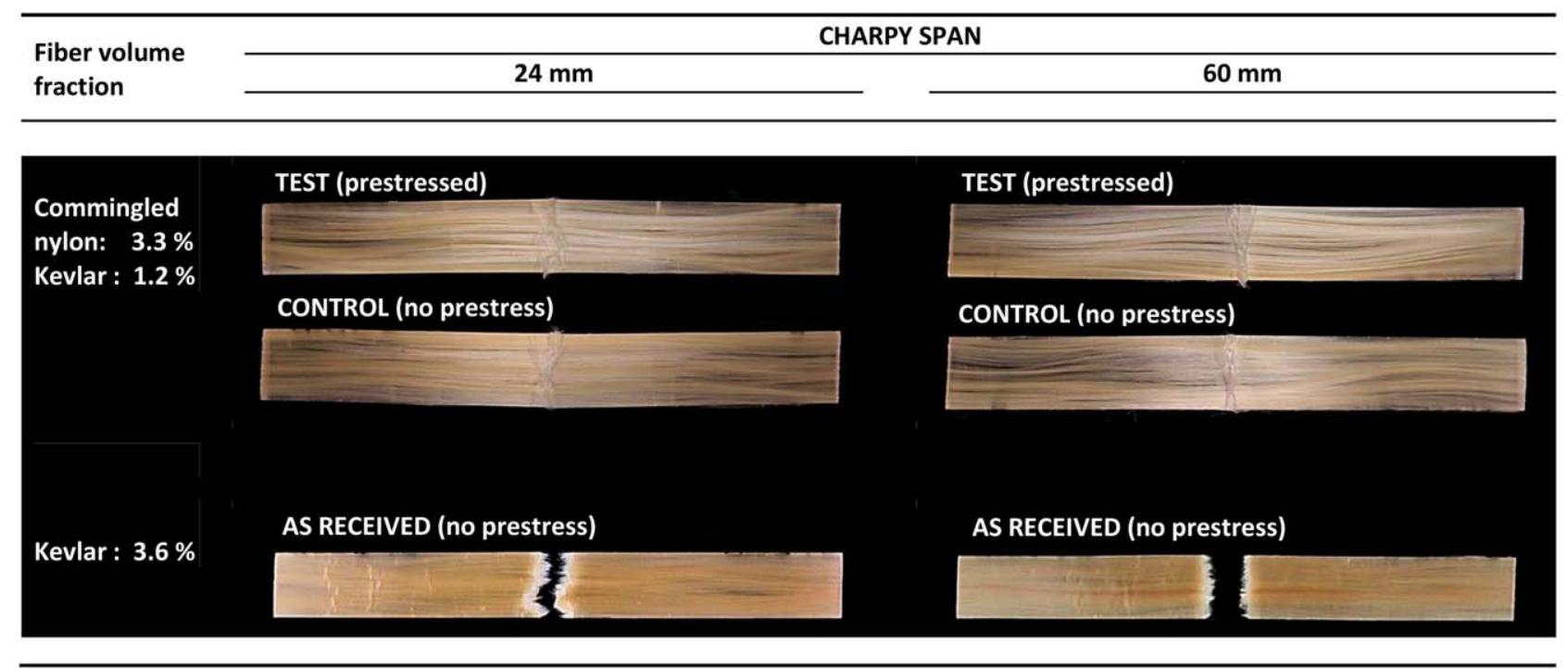

FIG. 4. Typical hybrid and Kevlar fiber composite samples after Charpy impact testing at $24 \mathrm{~mm}$ and $60 \mathrm{~mm}$ span settings. [Color figure can be viewed in the online issue, which is available at wileyonlinelibrary.com.]

$1008 \mathrm{~h}$, increasing the mean test and control sample modulii by $\sim 11 \%$ and $\sim 3 \%$ respectively. The effect raises the average pre-stress-induced increase in modulus from $\sim 37 \%$ (336 h) to $\sim 47 \%$ (1008 h).

Figure 5 shows modulus data from the hybrid samples (Table 3) and, for comparison, results from the resin-only samples. At $1008 \mathrm{~h}$, the mean resin-only modulus (2.62 $\mathrm{GPa})$ is $\sim 5 \%$ higher than the result at $336 \mathrm{~h}(2.51 \mathrm{GPa})$. This could suggest that longer term changes within the resin may have contributed towards the slight increase in modulus observed with some hybrid samples at $1008 \mathrm{~h}$. Nevertheless, statistical hypothesis tests (5\% level) to compare the hybrid sample modulus means (test and control) between 336 and 1008 h show no significant differences. Therefore, the higher pre-stress-induced increase in modulus at $1008 \mathrm{~h}$ can be attributed to measurement variations.

\section{DISCUSSION}

\section{Impact Energy Absorption}

As shown in Fig. 4, there are clear differences in fracture characteristics between the Kevlar fiber-only and hybrid samples. The low $V_{\mathrm{f}}$ and unidirectional fiber layup used here may have exacerbated the brittle fracture characteristics of the Kevlar fiber samples. In other work [26], Charpy tests on woven aramid fiber unnotched composites with higher $V_{\mathrm{f}}(55 \%)$ exhibited only partial fracture, the pendulum hammer driving the damaged specimens between the anvil shoulders. Clearly, this drag effect influences the measured impact energy and, although the $V_{\mathrm{f}}$ values used in our work may be criticized for being unrealistically low, the contribution from drag on hinged-break samples, especially at $24 \mathrm{~mm} \mathrm{span,} \mathrm{is}$ minimized [12].

The hinged-break fracture characteristics of the hybrid samples at $24 \mathrm{~mm}$ span in Fig. 4 are similar to those observed with nylon 6,6 fiber-only samples from Ref. [12]. They show a main central crack (from direct contact with the Charpy hammer) and, although barely visible in Fig. 4, secondary cracks in the vicinity of the anvil shoulders. In Fig. 3a however, there is less energy absorbed by the hybrid samples compared with those of only nylon fiber. Since this reduction occurs in both test and control groups, we suggest that the addition of (relatively stiff and brittle) Kevlar fibers may attenuate

TABLE 3. Flexural modulus results from three-point bend tests on individual hybrid composite samples.

\begin{tabular}{|c|c|c|c|c|c|c|}
\hline & \multicolumn{3}{|c|}{$336 \mathrm{~h}$} & \multicolumn{3}{|c|}{$1008 \mathrm{~h}$} \\
\hline & \multicolumn{2}{|c|}{ Flexural modulus (GPa) } & \multirow[b]{2}{*}{ Increase $(\%)$} & \multicolumn{2}{|c|}{ Flexural modulus (GPa) } & \multirow[b]{2}{*}{ Increase $(\%)$} \\
\hline & Test & Control & & Test & Control & \\
\hline & 4.62 & 2.96 & 55.8 & 5.39 & 3.29 & 63.6 \\
\hline & 4.55 & 3.59 & 26.9 & 4.55 & 3.59 & 26.9 \\
\hline & 4.18 & 3.28 & 27.7 & 4.88 & 3.28 & 48.9 \\
\hline Mean \pm SE & $4.45 \pm 0.14$ & $3.28 \pm 0.18$ & $36.8 \pm 9.5$ & $4.94 \pm 0.24$ & $3.39 \pm 0.10$ & $46.5 \pm 10.7$ \\
\hline
\end{tabular}

Equivalent mean modulus results from three resin-only samples were $2.51 \pm 0.05 \mathrm{GPa}(336 \mathrm{~h})$ and $2.62 \pm 0.11 \mathrm{GPa}(1008 \mathrm{~h})$. SE is the standard error of the mean. 


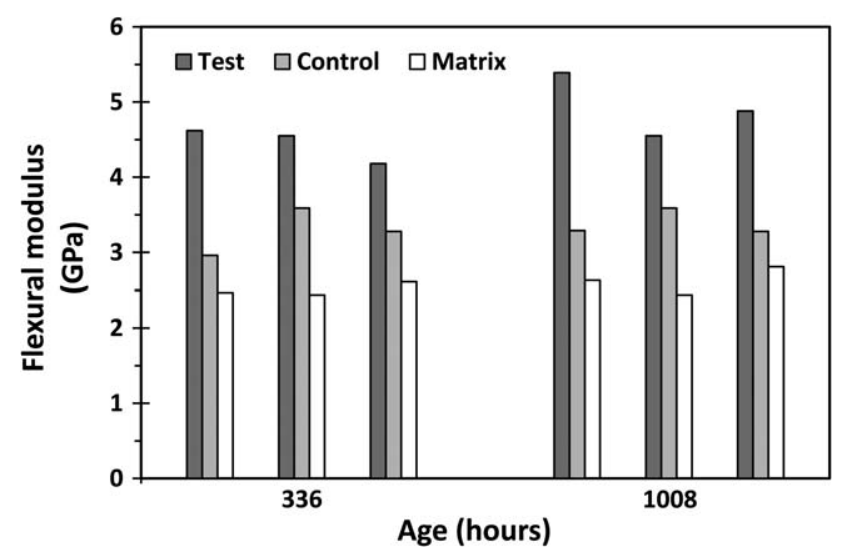

FIG. 5. Flexural modulus data (individual samples) at $336 \mathrm{~h}$ and 1008 $\mathrm{h}$ from Table 3, and equivalent data from resin-only samples for comparison.

energy-absorbing behavior from the nylon fibers, possibly by (i) constraining their shear strain levels, hence less debonding during impact or (ii) shockwaves from fracturing Kevlar fibers promoting nylon fiber fractures over debonding. Nevertheless, as denoted by increased energy absorption from the hybrid test samples (Table 1, Fig. 3a), the pre-stress-induced energy absorbing mechanism (i.e., residual shear stresses at the fiber-matrix interface regions promoting energy absorbing fiber debonding over transverse fracture) appears to remain effective. This is despite the correspondingly greater debonded region in the test sample at $24 \mathrm{~mm}$ span in Fig. 4 being less pronounced than that generally observed with nylon 6,6 fiber-only samples [7-12].

For nylon fiber-only composites at $60 \mathrm{~mm}$ span, energy absorption through elastic deflection (as the sample is forced through the anvil shoulders) was considered to be significant, with less contribution from fractureinducing (plastic) deformation, especially from pre-stressinduced debonding [12]. This explains the lower energy absorption and zero increase from pre-stress effects observed in Fig. 3b compared with the results in Fig. 3a for these composites. Although the hybrid results in Fig. $3 \mathrm{~b}$ also show lower energy absorption compared with Fig. $3 \mathrm{a}$, the reduction is smaller and there is still a positive pre-stress-induced energy increase. We suggest here that the (stiff) Kevlar fibers will have suppressed elastic deflection to some extent, thereby promoting more energy absorption from fracture and debonding.

\section{Flexural Stiffness}

The increases in flexural modulus (Table 3, Fig. 5) are comparable to previous VPPMC studies [14, 15], i.e., there are no indications that the addition of Kevlar fibers has detrimentally affected the viscoelastic pre-stress effect. The modulus increases may be attributed to the three mechanisms proposed in earlier work, as reported in the "Background" section, i.e., (i) deflection-dependent forces opposing the applied bending load, (ii) a more collective response to bending forces from the pre-tensioned fibers, and (iii) pre-stress-induced shifting of the neutral axis in bending. Nevertheless, these mechanisms were originally speculated to explain pre-stress-induced increases in bending stiffness from composite cross-sections that had nearuniform fiber spatial distributions [14].

Figure 2 clearly shows non-uniform fiber spatial distributions, with the greatest fiber concentration lying close to the lower surface, i.e. the tensile region during three-point bend testing. Similar non-uniform distributions were observed with polyethylene fiber composites [15] and, for both test and control samples, the effect will clearly influence the contribution represented by $I$ in $E q$. 1 . For the test samples, however, since compressive stresses from fibers are concentrated in the tensile region during bending, there is a direct contribution to increased flexural modulus.

\section{Commingled VPPMCs as Practical Composite Structures}

One of the principal findings from recent work on nylon 6,6 fiber-only composites was that elastic deflection during impact would reduce improvements to energy absorption from pre-stress effects [12]. As discussed earlier, although a similar effect is observed with the hybrid samples (comparing results at 24 and $60 \mathrm{~mm}$ spans), the addition of Kevlar fibers reduces the problem. Clearly, for structures where deflection is limited, low velocity impact protection will be further improved by VPPMC technology and commingling the low modulus pre-stressgenerating nylon fibers with high modulus fibers such as Kevlar, carbon, or glass, may offer a practical solution to restricting deflection during impact.

Our work has investigated commingled composites in which both types of fiber run parallel with each other. We suggest however that novel hybrid VPPMC structures could be created by running the pre-stress-generating fibers in directions different to other fibers. One application might be morphing structures. Non-symmetrical multilayer laminate composites can produce residual stresses (e.g., from thermal effects during molding) and these can be exploited to create multi-stable deformations [27]. Elastic pre-stress-generating fibers can be incorporated to create similar effects in symmetrical laminates [28], thus alternatively, VPPMC techniques could be applied. Morphing aircraft wings, in which elastically pre-stressed carbon fiber composite strips are enclosed within a nylon fiber-reinforced skin [29], may benefit from VPPMC technology if it provides, for example, opportunities for simplified construction.

\section{CONCLUSIONS}

Charpy impact testing (24 and $60 \mathrm{~mm}$ spans) and three-point bend-tests have been used to investigate hybrid VPPMCs consisting of unidirectional commingled 
nylon 6,6/Kevlar-29 fibers. A low $V_{\mathrm{f}}$ was used $(3.3 \%$ nylon, $1.2 \%$ Kevlar), which minimized the contribution from drag, during Charpy tests, from hinged-break samples. Where appropriate, results from these hybrid composites were compared with single fiber-type samples. The main findings are as follows.

I. All Kevlar fiber-only samples $\left(3.6 \% V_{\mathrm{f}}\right)$ fractured into two pieces, with virtually no debonding, during impact testing at both spans. Thus at least for the low $V_{\mathrm{f}}$ used here, energy absorption was comparatively low and occurred through brittle fracture.

II. Charpy tests on the hybrid composites exhibited ductile fracture characteristics, producing hinged-break samples. Energy absorption through fiber-matrix debonding was significant, though the presence of Kevlar fibers made these debonded regions appear less pronounced compared with previous studies on non-hybrid composites. The prestressed (test) samples absorbed more energy with larger debonded regions than their control counterparts, consistent with the view (from earlier work) that residual shear stresses at the fiber-matrix interface regions promote energy absorbing debonding over transverse fracture.

III. For Charpy testing at $24 \mathrm{~mm}$ span, the hybrid samples absorb slightly less impact energy than corresponding nylon fiber-only samples. We attribute this to the Kevlar fibers attenuating the energy-absorbing behavior of the nylon fibers in the commingled case; however, prestress-induced increases in energy absorption are comparable, i.e., 33\% (hybrid) and 39\% (nylon fiber-only). At $60 \mathrm{~mm}$ span, the situation is reversed, in that the hybrid samples absorb slightly more energy; moreover, there is a small increase in pre-stress-induced energy absorption $(\sim 11 \%)$, compared with approximately zero increase in the nylon fiber-only samples. We suggest that the Kevlar fibers suppress elastic deflection at this wider span setting, thereby promoting more effective energy absorption from fracture and debonding.

IV. Bend tests on the hybrid composites demonstrated prestress-induced increases in flexural modulus of $\sim 37 \%$ at $336 \mathrm{~h}$ and $\sim 47 \%$ at $1008 \mathrm{~h}$. These differences can be attributed to measurement variations rather than any time-dependency. The addition of Kevlar fibers, at least for the low $V_{\mathrm{f}}$ studied here, does not appear to be detrimental to the increased stiffness benefits provided by viscoelastic pre-stress effects.

As a preliminary investigation, our findings are derived from tests on simple composite samples with unidirectional fiber reinforcement, restricted to a single nylon/ Kevlar fiber ratio at a low $V_{\mathrm{f}}$. Although more extensive investigations are required, the current results suggest that hybrid VPPMCs may provide a means to improve impact toughness and other mechanical characteristics for composite applications.

\section{ACKNOWLEDGMENTS}

The authors would like to thank Garry Robinson for technical support. School of Engineering support (PhD degree fee waiver) for one of the authors (AF) is gratefully acknowledged.

\section{REFERENCES}

1. M.R. Wisnom, M. Gigliotti, N. Ersoy, M. Campbell, and K.D. Potter, Compos. Part A, 37, 522 (2006).

2. D. Cohen, Compos. Part A, 28, 1035 (1997).

3. P. Mertiny and F. Ellyin, Compos. Part A, 33, 1615 (2002).

4. A.S. Hadi and J.N. Ashton, Compos. Struct., 40, 305 (1998).

5. S. Motahhari and J. Cameron, J. Reinf. Plast. Compos., 17, 123 (1998).

6. S. Motahhari and J. Cameron, J. Reinf. Plast. Compos., 18, 279 (1999).

7. K.S. Fancey, J. Adv. Mater., 37, 21 (2005).

8. K.S. Fancey, Mater. Sci. Eng. A, 279, 36 (2000).

9. K.S. Fancey, J. Reinf. Plast. Compos., 29, 1251 (2000).

10. J.W.C. Pang and K.S. Fancey, Mater. Sci. Eng. A, 431, 100 (2006).

11. K.S. Fancey, Compos. Part B, 41, 454 (2010).

12. A. Fazal and K.S. Fancey, Compos. Part B, 44, 472 (2013).

13. J.W.C. Pang and K.S. Fancey, Compos. Sci. Technol., 68, 1903 (2008).

14. J.W.C. Pang and K.S. Fancey, Compos. Part A, 40, 784 (2009).

15. A. Fazal and K.S. Fancey, J. Mater. Sci., 48, 5559 (2013).

16. H. Cui, M. Guan, Y. Zhu, and Z. Zhang, Key Eng. Mater., 517, 96 (2012).

17. M.H. Lafitte and A.R. Bunsell. Polym. Eng. Sci., 25, 182 (1985).

18. H. Knoester, P. den Decker, J. van den Heuvel, N. Tops, and F. Elkink, Macromol. Mater. Eng., 297, 559 (2012).

19. Goodfellow Cambridge Ltd, UK. Online catalogue (material properties) at http://www.goodfellow.com; accessed July 2013.

20. B.Z. Jang, L.C. Chen, C.Z. Wang, H.T. Lin, and R.H. Zee. Compos. Sci. Technol., 34, 305 (1989).

21. C. Thanomsilp, and P.J. Hogg, Compos. Sci. Technol., 63, 467 (2003).

22. Y. Cao and J. Cameron, J. Reinf. Plast. Compos., 25, 347 (2006).

23. P.J. Hine, R.A. Duckett, A.S.Kaddour, M.J. Hinton, and G.M. Wells, Compos. Part A, 36, 279 (2005).

24. S. Timoshenko, Strength of Materials, Part I. Elementary Theory and Problems, 3rd ed., Krieger, New York (1955) [1976 reprint].

25. J.W.C. Pang, B.M. Lamin, and K.S. Fancey, Mater. Lett., 62, 1693 (2008).

26. G. Faur-Csukat, Macromol. Symp., 239, 217 (2006).

27. W. Hufenbach and M. Gude, Compos. Struct., 55, 319 (2002).

28. S. Daynes, K.D. Potter, and P.M. Weaver, Compos. Sci. Technol., 68, 3431 (2008).

29. S. Daynes, X. Lachenal, and P.M. Weaver, Proceedings of the 23rd International Conference on Adaptive Structures and Technologies (ICAST 2012), Nanjing, China, 1-11 (2012). 